\title{
Tamanho é documento: narrativas de homens que sofreram amputação por câncer de
}

\section{pênis}

\author{
Size matters: narratives of men who have been amputaded as a result of penile cancer \\ Tamaño y documento: narrativas de hombres que sufrieron amputación por cáncer de pene
}

Leudivan Ribeiro Nogueira

ORCID: https://orcid.org/0000-0003-2197-689X Universidade CEUMA, Brasil.

E-mail: leudivan.nogueira@gmail.com

Raquel Moraes da Rocha Nogueira

ORCID: https://orcid.org/0000-0002-9975-5539 Universidade CEUMA, Brasil

E-mail: raquelreumato@bol.com.br

Marcos Antônio Barbosa Pacheco ORCID: https://orcid.org/0000-0002-3566-5462 Universidade CEUMA, Brasil E-mail: mmmarco@terra.com.br

Claudia Barbastefano Monteiro ORCID: https://orcid.org/0000-0002-3150-7424 Universidade Federal do Rio de Janeiro, Brasil E-mail: claudia.ipub@gmail.com

Cristina Maria Douat Loyola ORCID: https://orcid.org/0000-0003-2824-6531 Universidade CEUMA, Brasil E-mail: crisloyola@hotmail.com

\begin{abstract}
Resumo
Objetivo: A presente pesquisa objetivou discutir as razões da demora em procurar assistência em saúde para câncer de pênis. Estabeleceu-se como objetivos secundários listar fatores subjetivos e objetivos que influenciam na demora em acessar o SUS para o diagnóstico do câncer de pênis, analisar fatores culturais individuais e coletivos na construção da imagem do homem com câncer de pênis. Métodos: Tratou-se de uma pesquisa qualitativa, descritiva, exploratória, de natureza analítica com quatorze entrevistados, utilizando-se da análise temática e apoiando-se na teoria das representações sociais. Resultados: $\mathrm{O}$ estudo foi composto por adultos jovens e sexagenários, idade variando entre $35 \mathrm{e}$ 70 anos, com diagnóstico de câncer de pênis, a maior parte dos entrevistados cursou apenas ensino fundamental incompleto e são católicos, com rendimentos entre um ou dois salários-mínimos. Elaboramos duas categorias de análise que abrangem diferentes temporalidades da doença. A primeira referente ao momento anterior ao diagnóstico de câncer de pênis que nomeamos de "borbulha da natureza", "tamanho é documento"? referente ao período posterior ao diagnóstico de câncer. Considerações finais: Podemos afirmar a partir da narrativa dos entrevistados que a ideia fundamental, sobre o câncer de pênis e a cirurgia de amputação, é o medo de perder tamanho no pênis.
\end{abstract}

Palavras-chave: Câncer de pênis; Teoria das representações sociais; Amputação.

\begin{abstract}
Objective: The present research is aimed at discussing the reasons behind patients' delayed initiative in seeking healthcare assistance for penile cancer. It was established as secondary objectives to list subjective factors that influence the delayed initiative in accessing SUS (Brazil's public healthcare system) for the diagnosis of penile cancer, to analyze individual and collective cultural factors leading to the image construction of the man with penile cancer. Method: It was a qualitative, descriptive, exploratory, analytical research with fourteen interviewees, using thematic analysis as well as the support of the theory of social representations. Results: The study was comprised of young adults and men who are in their sixties, aged 35 to 70, diagnosed with penile cancer, most interviewees attended only incomplete elementary school and are Catholics, with a monthly income around one or two minimum wages. We produced two categories of analysis that cover different temporalities of the disease. The first one regarding the moment prior to the diagnosis of penile cancer, which we have named as a "pimple in nature"; "Does size matter"? referring to the period after cancer has been diagnosed. Final Considerations: We can state after hearing the interviewees that the fundamental idea about penile cancer and the amputation surgery is the fear of losing size, thus having a smaller.
\end{abstract}

Keywords: Cancer of the pênis; Theory of social representations; Amputation. 


\begin{abstract}
Resumen
Objetivo: El presente estudio tiene como objetivo discutir las razones de la demora en buscar atención médica para el cáncer de pene. Se estableció como objetivo secundario enumerar los factores subjetivos y objetivos que influyen en la demora en accesar al Sistema Público de Salud, para el diagnóstico de cáncer de pene. Se analizan factores culturales individuales y colectivos en la construcción de la imagen del hombre con cáncer de pene. Métodos: Se trató de un estudio cualitativo, descriptivo, exploratorio, de naturaleza analítica con catorce entrevistados. Se utilizó un análisis temático, apoyándose en la teoría de las Representaciones Sociales. El estudio fue compuesto por adultos, jóvenes y sexagenarios, con edades variando entre 35 a 70 años, con diagnóstico de cáncer de pene, la mayor parte de los entrevistados cursó apenas educación primaria incompleta y con ideología de índole católica, con sueldos entre 1 a 2 salarios mínimos. Resultados: Elaboramos dos categorías de análisis que abarcan diferentes temporalidades de la enfermedad. La primera es referente al momento anterior al diagnóstico de cáncer de pene, que nombraremos como "Burbuja de la Naturaleza”, así como “¿Tamaño es Documento?” referente al período posterior al diagnóstico de cáncer. El perfil de los entrevistados es de un hombre de baja renta, mínima escolaridad, residente en la zona rural, que se consulta con funcionarios de farmacia, que se vale de personas corruptas para conseguir burlar la entrada al sistema público de salud para consultarse, así como también desconoce el tema del cáncer de pene. Consideraciones finales: Podemos afirmar a partir de la narrativa de los entrevistados, que la idea fundamental sobre el cáncer de pene y la cirugía de amputación, es el miedo a perder el tamaño del pene.
\end{abstract}

Palabras clave: Cáncer de pene; Teoría de las representaciones sociales; Amputación.

\title{
1. Introdução
}

O câncer de pênis é uma doença rara em países desenvolvidos, a incidência aumenta em países africanos, asiáticos e da América do Sul. A taxa padronizada pela idade (ASR - Age Standardised Rate) para câncer de pênis é 0,5 nos Estados Unidos, 7.0 em Eswatini/África, 4,6 em Uganda/África e de 1,3 casos no Brasil para 100.000 homens (Globocan, 2021).

Analisaram-se 392 casos de câncer de pênis entre 2004 e 2014 e constataram uma incidência mínima ajustada para idade de 6,1/100.000 homens e uma incidência mínima bruta anual de 1,18/100.000 homens, conferindo ao Maranhão a maior incidência de câncer de pênis mundial, considerando dados de único centro de tratamento (Coelho et al., 2018). Também sabemos que há demora, em média 18 meses e 89 dias, entre o primeiro sintoma e o tratamento especializado na capital do Estado, o que vai implicar em diagnóstico avançado do caso e tratamentos cirúrgicos radicais (Vieira et al., 2020).

Segundo o Consenso Brasileiro de Câncer de Pênis a incidência reduz-se com o incentivo da circuncisão neonatal, cessação do tabagismo, vacinação contra o HPV, prevenção de outras infecções sexualmente transmissíveis com uso de preservativos, diagnóstico precoce e melhor higiene local (Soares et al., 2020).

O tratamento do câncer de pênis pode variar desde tratamentos tópicos e glandectomias (exérese da glande) até as amputações parciais ou totais do pênis em tumores mais avançados. A linfadenectomia inguinal bilateral complementa o tratamento nos tumores com suspeita de metástases, assim como a quimioterapia e/ou radioterapia (Soares et al., 2020). Tratamentos mais agressivos relacionam-se com piora na qualidade de vida, alteração na aparência física da área genital, disfunção sexual e miccional além de prejuízo na autoestima (Audenet \& Sfakianos, 2017).

A procura dos homens pela assistência à saúde na atenção primária, não só em relação ao câncer de pênis, mas em relação aos agravos a saúde é uma barreira que os leva a acessar o sistema único de saúde (SUS) pela média e alta complexidade com baixa procura pela atenção primaria (Schraiber et al., 2010). Diante desse cenário de ausência de políticas destinada aos homens, em 27 de agosto de 2009, através da portaria N 1.944, institui-se a Política Nacional de Atenção Integral à Saúde do homem (PNAISH) como ferramenta legal de promoção a saúde do homem e de qualificação das equipes de saúde para melhor acolhimento (Ministério da Saúde, 2008).

Os fatores que contribuem para o atraso dos homens na procura por assistência médica são variados: falta de tempo em razão do trabalho, Unidade Básica de Saúde como espaço mais feminino, sensação de não pertencimento e de invisibilidade, além de existirem mais campanhas e políticas de promoção da saúde para as mulheres (Carneiro et al, 2019).

Outro componente importante para retardar os cuidados com a saúde na população masculina encontra-se na vivência da cultura machista, reproduzida no estereótipo da masculinidade hegemônica, presente no interior do Nordeste brasileiro, que 
atribui ao homem características como força, virilidade, racionalidade, sexualidade exacerbada e percepção de que não há motivos para a prevenção das doenças (Carneiro et al, 2019; Medeiros \& Cabral, 2019; Separavich \& Canesqui, 2013; Silva et al., 2015).

No contexto social, a sexualidade é associada à estética do corpo e ao exibicionismo dos órgãos genitais que se utiliza do erotismo como mola propulsora do consumo na atualidade. A filosofia nos mostra que a sexualidade perpassa pelos ensinamentos da igreja católica, do cristianismo, desde o estoicismo até diretrizes recentes do Conselho Pontifício para a Família, e pelo reconhecimento antropológico que sexualidade vai além do biológico. A psicologia sobre a sexualidade é amparada na teoria da sexualidade de Freud, onde a sexualidade se estrutura como base para o desenvolvimento psíquico do indivíduo. A relação da sexualidade com a ética se faz presente à medida que se considera a outra pessoa e não meramente um produto descartável (Santos, 2020).

Os homens que se submeteram a tratamentos oncológicos diversos expressam alterações biopsicossociais que impactam a expressão da sexualidade e neste processo a participação da parceira sexual mostra-se impactando a qualidade de vida e convalescença pós-tratamento em relação à sexualidade (Souza et al, 2019).

Ao longo da história o pênis foi representado majoritariamente ereto em imagens, pinturas, esculturas ou em objetos dissimulando a ereção em épocas e civilizações diferentes. Em pinturas rupestres da gruta de Lascaux, localizada no departamento da Dordogne na França, datados da pré-história, encontra-se um homem deitado com o pênis ereto ao lado de um bisão. Na mitologia grega, Príapo apresentava-se com um falo desproporcional ao seu corpo. No Império Romano, havia a imagem de falo gigante nos afrescos na casa de Vetti, um prostíbulo em Pompéia. Após a queda do Império Romano e ascensão do cristianismo, Santo Agostino recoloca em discussão o pudor e o pecado. O pênis aparece com despudor nos estudos renascentistas de Leonardo da Vinci através de gravuras que retratavam o pênis ereto. No século XX. Freud desenvolve a teoria da sexualidade humana a partir do falo, que representará o pênis na teoria da castração se mostrará importante na constituição do sujeito (Pereira, 2000).

O pênis, ou falo, como conceito, vai impregnar não apenas o saber douto sobre o humano, mas também os saberes populares e sua função de teia de sustentação e de constituição das relações entre homens e mulheres e dos próprios homens entre eles mesmos. Neste sentido mostrou-se interessante trabalharmos com a teoria das representações sociais de Moscovici (2009).

A Teoria da Representações Sociais (TRS) fundamentou-se na tensão entre o pensamento científico e o pensamento quotidiano e apontou que a comunicação e a linguagem são os elos pelos quais as representações sociais são formadas, mantidas e modificadas (Marková, 2017)

Moscovici (2009) propõe que qualquer ideia, emoção, crença e cadeias completas como as ciências, religião, mito, estariam incluídas nas representações sociais, que funcionam coletivamente por meio de interações e comportamentos.

A partir da compreensão das representações sociais os pacientes oncológicos podem se beneficiar na identificação das construções negativas a respeito do câncer e auxiliar as equipes de saúde para que possam desconstruí-las e melhorar o enfrentamento da doença (Wakiuchi et al., 2020).

Esta possibilidade de tornar invisível um problema que é visível no corpo, a demora em procurar ajuda são produzidas por barreiras de ordem psíquica e cultural como a vergonha, o pudor, a fragilidade, a virilidade, a cultura machista, o medo de ser castrado?

Neste estudo espera-se trazer uma discussão para a compreensão do processo saúde-doença-cuidado, que ultrapasse as intervenções técnicas e racionais do modelo biomédico. Em algumas situações esta orientação médica pode se afastar da totalidade da pessoa, do contexto de suas vidas cotidianas, das relações sociais, da intersubjetividade e do complexo das condições sociais, culturais, morais e relacionais. A partir desta reflexão inicial elaboramos algumas questões norteadoras: 
- Porque o tumor palpável e visível no pênis e com odor forte, por quase dois anos, não tem potência para levar um homem ao médico?

- A quem se recorre em primeiro lugar para comentar sobre uma lesão que apareça no pênis? Qual a vivência física que levou à procura?

- O homem com câncer de pênis conhece o funcionamento do órgão genital masculino? Quais outros nomes são dados à glande, ao prepúcio e ao próprio pênis?

- O paciente com câncer de pênis sente se acolhido quando consegue acessar o SUS?

- Se dispuséssemos de um especialista médico urologista em cada UBS do estado do Maranhão a demora no atendimento dos pacientes diminuiria? Quem deu o diagnóstico?

- O paciente com câncer de pênis tem vergonha que mais pessoas conheçam o diagnóstico e o tratamento realizado? Quais representações sociais os pacientes elaboram sobre o câncer de pênis?

- Qual seria o entendimento de "ser castrado", de "ter um câncer", ou de risco de vida que possuem?

- O homem com câncer do pênis tem vergonha de falar sobre o tratamento realizado?

- Tem receio de que o tratamento da doença comprometa sua virilidade? O que ele pensa sobre sua sexualidade, masculinidade após a cirurgia?

Diante destas questões norteadoras este artigo objetiva discutir a demora em procurar assistência para câncer de pênis e as questões socioculturais que envolvem a cirurgia de amputação. Estabeleceu-se como objetivos secundários listar fatores objetivos e subjetivos que influenciam na demora em acessar o SUS para o diagnóstico do câncer de pênis, analisar fatores culturais individuais e coletivos na construção da imagem do homem com câncer de pênis, momento da consulta e do diagnóstico de câncer.

\section{Metodologia}

Trata-se de uma pesquisa qualitativa, descritiva, exploratória, de natureza analítica com 14 entrevistados, utilizando-se a análise de conteúdo para o material empírico e a teoria das representações sociais (TRS), a partir da abordagem de Moscovici, percebendo as condições e os processos implicados na construção de categorias coletivas de pensar e explicar o câncer de pênis (Moscovici, 2009).

A pesquisa foi realizada em um hospital público, na cidade de São Luís, com 14 indivíduos com câncer de pênis. Critérios de inclusão: possuir entre 18 anos e 80 anos, ter diagnóstico de câncer de pênis e ter se submetido a tratamento cirúrgico. Foram excluídos pacientes que fizeram outros tratamentos oncológicos ou que apresentaram prejuízo cognitivo que impossibilitasse a entrevista. O pesquisador foi o médico assistente e cirurgião de quatro entrevistados tendo estado ciente da influência desta posição diante dos entrevistados, sendo que os demais foram tratados por outros integrantes da equipe urológica do Hospital;

Optou-se por definir o número de entrevistados por inclusão progressiva interrompida pelo critério da saturação (Minayo, 2014).

Para a coleta de dados, utilizou-se entrevista semiestruturada, com uma parte inicial para coleta de dados sociodemográficos. O local da entrevista respeitou a escolha do entrevistado sendo que 6 entrevistas foram realizadas nas dependências do Hospital e as demais nas residências dos entrevistados. Nenhum entrevistado se recusou a participar e todos demonstram satisfação ao saber que suas informações poderiam ajudar outros homens com câncer de pênis. As entrevistas foram gravadas por meio de aparelho eletrônico para posterior transcrição e análise. Os entrevistados foram codificados pela letra P, seguidas pelo número arábico que condiz com a ordem cronológica da entrevista. 
O objetivo da análise de conteúdo, modalidade temática, foi compreender o homem oriundo do interior do estado do Maranhão sobre a vivência com câncer de pênis. Análise temática baseou-se em três etapas propostas por Minayo (2014): a préanálise, a codificação e a interpretação.

A pesquisa foi aprovada no CEP do CEUMA sob número CAAE 30631919.2.0000.5084.

\section{Resultados e Discussão}

O estudo foi composto por adultos jovens e sexagenários, idade variando entre 35 e 70 anos, com diagnóstico de câncer de pênis, sendo que a quase totalidade cursou apenas ensino fundamental incompleto. A maioria são católicos, com rendimentos de um salário-mínimo. A maioria não tinha informação de saúde sobre câncer de pênis, salvo através de alguns programas de rádio e televisão havendo citação sobre a importância da fala do oncologista Drauzio Varella na televisão que foi vista por alguns.

Todos os participantes submeteram-se a algum tipo de cirurgia que oscilou entre a amputação parcial ou total e linfadenectomia inguinal. O tempo de espera entre o primeiro sintoma, o prurido, e o primeiro atendimento com médico não especialista, em postos de saúde de suas cidades, ultrapassou seis meses. O atraso na consulta com o médico especialista foi maior, tendo ultrapassado mais de um ano em quase todos os casos (Tabela 1).

Tabela 1. Perfil sociodemográficos dos entrevistados.

\begin{tabular}{lllllllcc}
\hline Entrevistado & Idade & Religião & $\begin{array}{l}\text { Estado } \\
\text { civil }\end{array}$ & Profissão & Escolaridade & Rendimentos & Cirurgia & Proc. \\
\hline P1 & 70 & C & Casado & Lavrador-A & EF-I & 1 SAL & AT & R \\
P2 & 54 & C & Casado & Ferramenteiro & EF-I & 1 SAL & AP - Linf. & U \\
P3 & 61 & C & Casado & Lavrador & Analfabeto & 1 SAL & AP & R \\
P4 & 35 & C & Solteiro & Lavrador & EF-I & 1 SAL & AP & R \\
P5 & 64 & C & Solteiro & Lavrador-A & Analfabeto & 1 SAL & AP & R \\
P6 & 39 & C & Solteiro & Lavrador-A & EF-I & 1 SAL & AP - Linf. & R \\
P7 & 58 & Agnóstico & Solteiro & Lavrador-A & EF-I & $<1$ SAL & AT - Linf. & R \\
P8 & 62 & C & Casado & Lavrador & EF-I & 1 SAL & AP - Linf. & R \\
P9 & 70 & C & Casado & Pescador-A & EF-I & 1 SAL & AP & R \\
P10 & 59 & C & Divorciado & Lavrador & Analfabeto & $<1$ SAL & AP - Linf. & R \\
P11 & 48 & P & Casado & Lavrador & Analfabeto & 1 SAL & AP & R \\
P12 & 38 & C & Casado & Eletricista & EF-I & 1-2 SAL & AP - Linf. \\
P13 & 56 & C & Divorciado & Lavrador & EF-I & 1-2 SAL & AP - Linf. \\
P14 & 46 & P & Casado & Motorista & EF-Com & 1-2 SAL & AT - Linf. & U \\
\hline
\end{tabular}

Legendas: AP - Amputação parcial; AT - Amputação total; C - Católica; EF-Com - Ensino fundamental completo; EF-I - Ensino fundamental incompleto; Lavrador-A - Lavrador aposentado; Linf. - Linfadenectomia; Proc. - Procedência; P - Protestante; R - Rural; SAL - Salário; U - Urbano.

Fonte: Elaborado pelos autores a partir dos dados coletados nas entrevistas (2021).

O perfil do grupo entrevistado é composto por adultos jovens, maioria católicos, com renda de um salário-mínimo, residentes na zona rural de cidades do interior do estado do Maranhão, com baixo nível de escolaridade e com capacidade laborativa normal à época dos sintomas iniciais. Este perfil social de baixa escolaridade, baixa urbanidade e baixa condição econômica parece, de certa forma, traçar um percurso do homem que necessita de amputação do pênis. Este perfil sociodemográfico confirma os dados encontrados em estudo epidemiológico sobre câncer de pênis realizado no Maranhão 
(Lindoso et al., 2018), apontando o baixo grau de desenvolvimento em educação, saúde e renda, como fatores de risco para esta intervenção cirúrgica que pode ser prevenida com informação, acesso a saúde e melhor distribuição de renda. Vale ressaltar que independentemente do tipo de amputação realizada, mais da metade dos pacientes teve que submeter à retirada de linfonodos, o que vai comprometer a atividade laboral posterior, com possível edema de membros inferiores além de tornar mais grave a evolução da doença e possível metástase.

A partir da análise inicial dos dados empíricos elaboramos duas categorias de análise que abrangem diferentes temporalidades da doença. A primeira delas nomearemos de uma "borbulha na natureza", e descreveremos as narrativas referentes ao momento anterior ao diagnóstico de câncer com as várias nomeações sobre o pênis, a percepção sobre a doença, os primeiros sinais e sintomas, os profissionais acessíveis e os tratamentos profissionais e não profissionais realizados. O segundo momento é pós-cirúrgico, que intitularemos “Tamanho é documento?", e descreveremos as dificuldades narradas pelos homens, as questões da sexualidade e do trabalho e as relações com as parceiras sexuais, após o tratamento cirúrgico.

\section{Uma borbulha na natureza}

A nomeação do pênis pelos entrevistados apresentou variações de palavras tais como pica, rola, cacete, minhoca, birro e, em algumas falas, declaravam ter ouvido nomes como pipira e natureza:

\section{"Eles chamam pipira. Eu chamo natureza." (P4)}

Esta nomeação popular vai se apoiar em formatos cilíndricos, de consistência dura e potentes para muitas repetições do movimento: minhoca (anelídeo cilíndrico e alongado), pica (lança antiga), pipira (ave frugívora, de coloração preta e avermelhada, ave gulosa quando criada em cativeiro), cacete (pedaço de madeira, roliço), que são análogos ao formato cilíndrico, pontiagudo e à coloração e rigidez do pênis. Essas representações sociais são compartilhadas e transmitidas ao longo do tempo, pressupondo um homem potente sexualmente, apto ao sexo a qualquer momento e com um pênis com tamanho suficiente e rigidez necessária. É comum no nordeste brasileiro o pênis ter o apelido de nomes de aves, como a pipira (Silva \& Correia, 2021). Observa-se na composição de João do Vale e José Batista de 1962, a pipira em metáfora subjetiva, representando o pênis e seu poder, pois conforme a música foi apenas um "beliscão", mas que logo engravidou a jovem moça:

Mané tem um viveiro

Tem passarinho de toda qualidade

Zabelê, canarico, corrupião

Pipira, sabiá, tem azulão

Rosinha por lá brincando

Pipira the beliscou

O dedo inchava, ela chorava

Ai, ai, ai, dor!

O que é menina?

Foi a pipira de Mané me beliscou!

Já vi menina da carne reimosa

Pipira do bico venenoso

Deixou todo mundo em alvoroço

Que a menina tá inchando

Do dedo até o pé do pescoço 
Pro via disso lá no Bacabal

Ninguém pode ver outro engordando

Censura ai, meu Deus, que é um horror!

E fica o povo comentando

Mais um que a pipira beliscou

Vosmicê tá duvidando

Foi um que a pipira beliscou

E fica o povo comentando

Mais um que a pipira beliscou

Vosmicê tá duvidando

Mais um que a pipira beliscou. (Vale \& Batista, 1962)

A música de cantor popular famoso no Maranhão e no Brasil, brinca com as palavras em que a pipira (ave) representa o pênis, que com uma beliscada engravida, e é uma ave que realiza movimentos repetidos e incansáveis de beliscar. A ideia que temos é a do pênis grande, rígido e incansável, que com simples toque pode atravessar todo o canal vaginal e alcançar o colo do útero. Esta imagem também encontra registro antigo, percorrendo um tempo longo de 5 séculos 500 anos tamanha a força do imaginário coletivo sobre as dimensões do pênis, numa figura desenhada por Leonardo da Vinci em seus estudos sobre o corpo. Assinale-se o tamanho imaginário do pênis que pode atravessar uma mulher, e que vai marcar a força, a potência e a importância deste tamanho para o desempenho adequado.

Figura 1. Cópula.

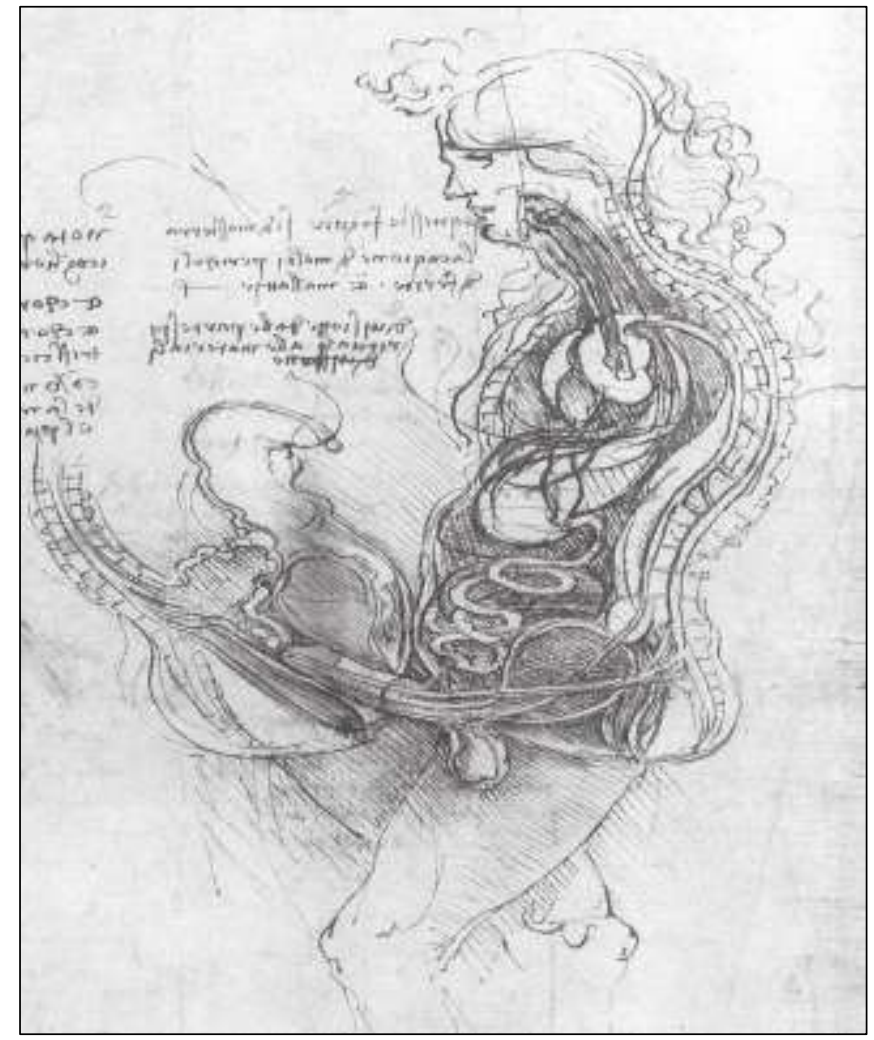

Fonte: Coition of a Hemisected Man and Woman (2021). 
As alterações na coloração da pele do pênis, o prurido ou lesões nodulares pequenas, semelhante a verrugas e bolhas, não pareciam ter potência para demandar cuidados médicos. Os primeiros sinais percebidos no pênis se localizavam estritamente na pele, com alteração na coloração, textura, prurido e no tamanho das lesões, do tipo nódulo:

“Não estou bem lembrado, mas eu...eu senti que tinha um pequeno caroçozinho, miudinho mesmo, num tem?! Mas num me lembro bem como foi que surgiu. Uma coceira, aí depois também quando eu coçava e coisava...aí parava, aí sumia também de novo, de repente tornava..." (P6)

"Pra era assim aquele negócio que tem, que fala que é doença até em cavalo, esquentamento, tem... esse... aquele negócio duma fogo selvagem" (P9)

Os sintomas do câncer de pênis embora percebido por muitos familiares não motivaram os entrevistados a buscarem atendimento médico especializado na fase inicial da doença. Esta decisão será tomada a partir da evidência do crescimento do tumor. A desconfiança de ser uma infecção sexualmente transmissível, e possivelmente adquirida por relação sexual fora do casamento, e sua perturbação sobre a ordem do laço matrimonial, representou fator de risco para um diagnóstico precoce. Havendo dúvidas quanto a uma possível infidelidade e ao temor de perturbação no casamento, não procuraram ajuda. As representações sociais sobre as infecções sexualmente transmissíveis, em especial a sífilis, guardam o temor dos segredos descobertos. A sífilis, descrita como doença secreta, contraída mediante relações sexuais fora do casamento, e que por vezes precisa ser escondida do médico, só se torna pública, com a manifestação dos exantemas sifilíticos, e a partir daí, a procura por ajuda médica (Carrara, 1996). As representações sociais (Jodelet, 2003) nos informam que o objeto que se relaciona com o sujeito pode ser material ou psíquico ou até uma ideia, portanto há aproximação da fase inicial da sífilis com câncer de pênis, assim como do momento em que o sifilítico e o portador de lesão ulcerada saem do anonimato e buscam ajuda médica.

Os relatos mostram que os nomes atribuídos ao tumor seguem a aparência da lesão como bolhas e nódulos, havendo analogia a formas como" pipoca com pus", "grane" (semelhante a grão) e "bolinha amarelada". Verifica-se em algumas falas a nomeação da lesão no diminuitivo, apontando a importância das dimensões do tumor para os entrevistados, entretanto com ausência total da noção de malignidade do sintoma:

“Começava a coceira e começava a borbulha, né?!” (P3)

“Uma bolha. Tipo assim um caroço. Aquela bolhazilha, aí formou no caroço. Caroço seco.” (P5)

"Bolo de carne. Tipo verruga. Aí por cima da cabeça do pênis criou uma 'brobulha' d'água." (P7)

Outro aspecto a ser considerado é a convivência com a doença nas fases iniciais, sem dor, que poderia ser entendida como autocuidado. Trata-se, possivelmente, de representação social sobre a baixa severidade de lesões na pele, que úlceras ou ferimentos de pequenas dimensões não são graves ou da concepção de masculinidade hegemônica por se tratar da região genital. Segundo Silva et al. (2021), a virilidade exacerbada contribui para um prejuízo no autocuidado que tem a higiene corporal um dos seus pilares, que por sua vez é um fator de risco para câncer de pênis conforme Soares et al. (2020).

Após um período convivendo com a lesão no pênis, não há avaliação crítica sobre a gravidade da doença que só vais aparecer com novos sintomas como sangramento, dor, abscesso (coleção de pus) e pelo aumento das dimensões da lesão inicial, despertando a busca por um tratamento médico: 
"Ela doía. A doer. Porque batia na roupa." Ela com o tempo ela foi crescendo mais um pouco, ai foi o tempo que a doutora foi pra lá e... aí ela viu, eu amostrei pra ela na consulta, ela olhou, aí... ela também não falou nada, só fez olhar porque... não explicou. Que gente do mato não pode saber." (P1)

"Saiu é... ele era só na pele...depois ele... feriu, cresceu um pouco." Ai eu procurei um hospital imediatamente." (P1) "Aí começou ferir, aí quando foi eu fui procurar o médico." (P7)

O crescimento do tumor provoca dor e sangramento limitando a capacidade laborativa e como estes pacientes ocupam posição econômica de provedores da família acabam impelidos a procurar assistência médica por questões socioeconômicas, de dificuldade no trabalho. Até esse momento os entrevistados não suspeitam de câncer de pênis, e comportam-se como se se tratasse de uma infecção sexualmente transmitida (IST) ou qualquer outra lesão da pele, não aventando ainda a ocorrência de um câncer. Segundo Lopes et al. (2017) e Schraiber et al. (2010), a dor é um sintoma que desencadeia nos homens a busca pelo atendimento médico, pois limita os afazeres diários, e por conseguinte, a renda familiar, semelhante ao encontrado nesta pesquisa. Podemos pensar que no caso de câncer de pênis a procura médica especializada se faz por dificuldades socioeconômicas e não por demanda de saúde.

Alguns participantes deste estudo relutavam em compartilhar as alterações iniciais no pênis com membros da família. A esposa nem sempre foi a primeira confidente, tendo havido relatos de confidências com irmã, amigo, pai e até com patrão sobre as lesões em fase inicial, onde até houve orientação para busca de ajuda médica:

"Falei pra um amigo meu lá de Mendonça. Ele disse "tu tem que 'precurar' um doutor que isso num é normal não". Mostrei pro meu pai ainda". (P4)

“Eles sempre me deram muita força, muito apoio, mas só que quando eu 'amostrei' só pro meu primo, minha irmã que soube que era um câncer de pênis". (P6)

Houve caso em que o participante escondeu a presença do tumor da esposa, pois acreditava tratar-se de uma infecção sexualmente transmissível e que essa informação poderia gerar desgaste no casamento:

"Poderia pensar, no meu caso, poderia pensar que fosse alguma doença que eu tivesse pegado de alguém. Até porque eu não mostrei, doutor, eu achava que assim que fosse causar um 'pobrema' ela acho que queria até assim... querer achar que fosse alguma coisa que eu tivesse... querendo dizer assim... acho que pudesse existir até uma separação." (P8)

As mulheres parceiras sexuais estáveis ou não podem ser a primeira linha de ação no combate ao câncer de pênis, pois são detentoras de vivência nos cuidados com a saúde dos filhos desde o nascimento até a adolescência. A partir desse entendimento, alguns estados do Brasil implantaram o "pré-natal masculino", que seria o momento em que o homem acompanharia sua esposa nas consultas do pré-natal e dessa forma pudesse realizar consultas preventivas, com exames laboratoriais, inclusive para infecções sexualmente transmissíveis (Alves et al., 2021). Outra inciativa que poderia ser seguida é a instituição do "novembrinho azul", campanha análoga ao novembro azul, com intuito de fomentar, desde a adolescência, a promoção da saúde do homem. O "novembrinho azul” é uma iniciativa que já existe em alguns estados com bons resultados (Lei $\left.n^{\circ} 8362,2016\right)$. 
Antes do primeiro atendimento médico, alguns entrevistados optaram por tratar sozinhos a lesão principal, seja extirpando-as com lâmina de barbear ou facas afiadas, seja colocando substâncias como talco e cinza de cigarro, buscando a cicatrização ou a redução total ou parcial do tumor:

“...mas além dessa mancha branca, ela era áspera. Saía umas cascas tipo umas escalas. E eu fazia o quêe?! Eu raspava com o barbeador." (P2)

"Ai um dia quando já tava grande, ai fui na farmácia, comprei 2 anestesias, ai 'apriquei', pra ver se eu dava jeito e eu cortava. Uma parte eu cortei deu certo. Primeiro enchi o banheiro de água, e aí amolei a faca também, uma gilete novinha." (P7)

"Tenta botar uma cinzazinha de cigarro." (P8)

Os entrevistados que realizaram tentativas de extirpação do tumor não objetivavam se livrar da doença em si, talvez a motivação maior fosse a manutenção do aspecto visual do pênis conforme a masculinidade hegemônica determina, mas não avaliavam que estavam diante de doença grave e mortal. A prática de tratamento local de úlceras remonta à medicina popular de origem africana, na qual os raizeiros tratavam a sífilis com cinza de cigarro segundo Hurston (2021), sugerindo como uma prática secular permanece impregnando o senso comum dos grupos sociais.

Alguns entrevistados, após a percepção do crescimento do tumor, recorreram aos balconistas da farmácia, na expectativa de um tratamento antes da consulta com os médicos. As ajudas obtidas variaram, entre prescrição de medicamentos via oral e injetáveis até uso de pomadas:

“...Começou numa coceira e eu me descuidei, né?! Porque eu ia na farmácia, o rapaz passava um remédio e aquilo aliviava, né?! Procurava só o farmacêutico. Eu mostrei pra ele, ele disse assim: 'Esse remédio aqui vai ficar bom!'e deu a injeção. Via. Eu mostrei, chamei ele lá no particular, aqui tem um reservado, aí fomos e mostrei. 'Você vai ficar bonzinho'. Injeção e passou uns comprimido." (P3)

A presença do balconista ou do próprio farmacêutico é uma figura comum no cotidiano das cidades do interior do Maranhão, porque atendem mesmo fora do horário comercial, nos finais de semana e por vezes a farmácia é uma dependência da residência do proprietário ou do farmacêutico ou do balconista. O balconista pode ser treinado a avaliar lesão cancerígena, assim como os agentes comunitários de saúde são treinados para avaliar manchas sugestivas de hanseníase, onde o que se ressalta é a sua fabulosa capilaridade facilitando o diagnóstico precoce do câncer de pênis. A prática da Atenção Farmacêutica preconiza que o farmacêutico contribuirá não apenas dispensando medicamentos, mas contribuindo com a saúde da comunidade (Pinto et al., 2021).

Na sequência dos tratamentos sem sucesso, a busca pelo atendimento médico começa a tornar-se uma necessidade que vai incentivar os muitos obstáculos que apresentar-se-ão. Ressalte-se que os primeiros médicos que atenderam esses pacientes não diagnosticaram, ou suspeitaram de lesão tumoral, tendo havido tratamentos com pomada antifúngica ou para doença sexualmente transmissível, o que nos remete a uma premente discussão sobre a formação médica para a atenção primária em saúde:

"Aí o caso é a gente partir pra um médico pra ver o que tá acontecendo, porque se a doutora me fala logo que era esse 'pobrema' no começo pra eu procurar logo, tinha procurado, mas como ela não falou nada eu também me acomodei. 
Aí eu trabalhando com roça.. Pois é... mas nada, ela não falou nada. Então eu fiquei pensando de ser alguma coisinha pouca." (P1)

“Não. Ele não identificou. Era o médico do sindicato.” (P2)

“Ele só disse assim: 'Aqui é uma verruga, isso daqui trata ligeirinho” aí ele me mandou pra secretaria." (P3)

“Aí um doutor lá que se chama doutor ' $R$ ' me passou uma pomada. Quadriderme. Ele só passou, disse: 'Passa essa pomada aqui que tu vai ficar bom." (P5)

Há pacientes que não foram examinados na primeira consulta, outros que durante a consulta não lhes foi solicitado tirar a calça para exame e que relataram terem sido encaminhados para um especialista, via Sistema Único de Saúde (SUS), na capital do estado, sem informação sobre a doença e sem informação sobre a suspeita de lesão neoplásica:

"Não. Só olhou e pronto. Aí disse que era pra mim entregar aquele papel na secretaria, quando a moça receber sabia o que fazer. Aí pá entrego pra moça da secretaria." (P7)

“Doutor, eu acho que eu consultei umas... seteloito vez. Não, nenhum momento ele falou não.” (P6)

Há relato de condescendência com a dificuldade de não diagnosticar a lesão como possivelmente cancerígena, através de observação simplória e resignada:

"Eu acho, doutor, eu acho que ele sabia, eu acho que ele ficou com medo de dizer pra mim. Só sendo. Porque um médico eu acho que ele conhece. Eu tenho certeza que um médico conhece." (P3)

A qualidade dos atendimentos médicos dos pacientes com câncer de pênis é passível de questionamento visto que o exame físico é parte da propedêutica de qualquer doença e não há justificativa para a sua não realização, que contribui para a demora no tratamento, pois a doença não é curável com cremes antifúngicos. Apresenta-se aqui a necessidade de rever a capacitação dos médicos para a Atenção Primaria, com vistas ao diagnóstico ou suspeição de câncer de pênis. A boa formação na graduação médica e a educação permanente melhoram o desempenho das equipes na atenção básica (Moreira et al., 2017) e poderão melhorar o diagnóstico precoce deste câncer comum no estado do Maranhão.

O SUS também apresenta problemas de encaminhamento e de lentidão no processo. Ao serem encaminhados para consulta especializada, os entrevistados enfrentaram demora no agendamento junto às secretarias municipais de saúde, com peregrinação de cidade em cidade, atrasando ainda mais o atendimento:

“Ele só me deu um encaminhamento. Aí eu também nem liguei pra encaminhamento não. Aí eu tornei lá de novo, aí ele me deu outro. Outro encaminhamento. Fui na secretaria de saúde, aí falei com a secretária de lá, aí mandei pra Colinas, aí outro médico de lá me despachou." (P7)

Devido às dificuldades de acesso e resolutividade do sistema público, alguns entrevistados teriam que arcar com o tratamento particular o que não foi possível acontecer devido às precárias condições financeiras, tornando-os cativos das oportunidades e da resolutividade do SUS: 
"Ai no dia que eu fui receber o doutor disse: 'Olha, é o começo de câncer, mas tem jeito'. Desse jeito: 'Eu dou jeito aqui.. essa operação.' Tudo bem... 'Aí tal dia você vem aqui!', que é o plantão dele, né?! Aí eu fui, ele foi e disse assim: 'A operação eu faço, é 5mil.' ...eu: 'Doutor, eu não tenho esse dinheiro, doutor.” (P3)

"Aí a gente não tem dinheiro, a gente chega e tudo é difícil demais." (P5)

A presença de "atravessadores", personagens ilegais que agilizariam consulta no SUS mediante recebimento propina, e a influência de políticos locais foram citados como forma de obter um atendimento mais rápido no SUS, burlando algum cronograma já estabelecido:

"Não. O meu médico eu só encontrei você. E através dessa senhora lá no geral." (P5)

"Não. Aí nós demo 100 reais pra essa senhora na época pra ela... ela informou o médico que podia ser do meu causo. Aí no outro dia logo nós viemo aí ela nos jogou na suas mãos.” (P5)

"Mas aí é porque um cunhado meu tava ajeitando uma vereadora dele. Aí ele disse que era pra mim ir pra Teresina que lá tudo era de graça, só não os exames.” (P7)

Nesta pesquisa, emerge uma representação social a respeito do SUS, a partir das falas dos usuários, que o "SUS não funciona ", apoiados na dificuldade de agendamento das consultas, tendo que utilizar-se de meios escusos para conseguir o que é garantido por lei. Observa-se que princípios do SUS como a universalidade, equidade e a hierarquização são desrespeitados conforme preconiza a Lei 8080/90 propiciando o atraso no tratamento do câncer de pênis no Maranhão, cobrança paralela por atendimento no hospital público e influência de políticos como prática em um estado que figura, no cenário nacional, como aquele com a maior incidência de casos. Segundo Oliveira et al. (2017), em pesquisa sobre representação social do SUS acerca dos direitos assegurados a clientela há um desconhecimento entre os usuários. Vale ressaltar aqui a importante participação social nos conselhos municipais de saúde para estas denúncias e melhoria do sistema de saúde.

\section{Tamanho é documento?}

Ao serem informados do diagnóstico e tratamento do câncer de pênis a maioria dos entrevistados apresentou reação de medo de morrer e tristeza. Outros relatavam que não tinham medo e acreditavam na intervenção divina para a cura:

“Eu só fiquei com um pouco de medo de... só em falar em câncer o pessoal já fica assustado.”(P7)

"Eu fiquei um pouco "mei" (meio) triste depois. Pensei que eu ia viver ou morrer. Medo de não conseguir fazer a cirurgia também." (P6)

" Fiquei confiante. Fiquei com medo não. Eu acreditava que Deus e esse senhor vai me curar." (P1)

O diagnóstico e o tratamento de todos os tipos de câncer são impregnados por representações sociais que passam pela morte, e dentre elas destacamos um sentimento de finitude conforme Dib et al. (2020) menciona, embora nem todos os entrevistados neste estudo, tenham manifestado o medo da morte conforme algumas falas. Podemos pensar que tenham tido vivências diferenciadas, uma delas baseada na convicção, expressa por alguns, de que não sabiam que seria possível ter câncer no pênis, uma localização anatômica que estaria a salvo deste mal. Interessante pensar que uma parte do corpo esteja protegida do câncer por motivos de natureza subjetiva e possivelmente apoiada no imaginário do senso comum sobre importância deste 
órgão que o colocaria a salvo de uma doença cuja cirurgia é a amputação. Vale ressaltar que a questão dominante nas falas se ancora no tamanho do pênis, determinante maior da sua importância e força:

"Ouvia falar de todo tipo de câncer, mas de pênis não era muito comentado. É porque eu nunca tinha ouvido falar. De todo câncer do corpo a gente vê falar, mas de pênis não." (P2)

“Nos pulmões, no "figo” (figado)... muitas partes...Pênis não." (P7)

Há uma referência de consenso sobre as infecções sexualmente transmissíveis e a sua visibilidade no pênis, mas câncer, não:

“Eu sempre me preocupava muito em pegar AIDS, outras doenças venéreas, mas câncer não." (P6)

O tratamento cirúrgico que implica em amputação parcial ou total apontou no primeiro momento arrependimento, mas na sequência informavam que se fosse preciso fariam a cirurgia outra vez. Podemos pensar que a cirurgia é compreendida como a chance de permanecer vivo:

"É... eu me arrependi. Bom... se fosse preciso eu fazia."(P7)

Após tomarem conhecimento da doença, relatam que nos últimos anos tiveram mais acesso às informações sobre câncer de pênis em programas de rádio e televisão, e que o tema se tornou mais frequente:

"Tem um doutor que a gente assiste, doutor 'Claudio Varelo', não tem?!” (P5)

É possível pensar que não seja a ausência de campanhas publicitarias sobre prevenção do câncer de pênis que justifiquem totalmente o desconhecimento sobre a doença na medida em que existem, na mídia, diversas entidades médicas utilizando personalidades públicas e artistas em campanhas de marketing. O que é passível de crítica não é somente a quantidade de campanhas publicitárias, mas seu impacto nesta clientela rural e de baixa escolaridade que enfrenta desafios para acessar o SUS. E ainda há alguns que convivem com a doença alguns anos mesmo tendo acessado o sistema de saúde, porque ele se mostrou incompetente tanto para diagnosticar a doença quanto para tratá-la. E lida-se também com a dificuldade desta população de admitir que pode haver câncer no pênis. Então como prevenir uma doença se o paciente não sabe sequer que ela existe? A resposta necessita ser informada por estudos que trabalhem com as representações sociais sobre o pênis, constituídas por informações e opiniões trocadas ao longo do tempo e mediante a comunicação entre os indivíduos permanecendo instruindo a realidade até os dias atuais (Abric, 1994, citado em Sousa \& Souza, 2021, p. 5).

Há narrativa que aproxima cirurgia de mudança de sexo e homossexualidade e possibilidade de aumentar pênis amputado como forma de restaurar o tamanho:

“Só na televisão que a gente vê falar que... só nos programa... no programa do Ratinho, no programa do... do... Rodrigo Faro, é... que a gente vê falar que bota transplante de pêni na pessoa, mas é só naqueles boiola que nasce homi e aí vira mulher." (P7)

As alterações no formato do jato urinário, às vezes fino ou como spray (espalhado e em oposição ao jato uni direcionado do pênis íntegro), e a mudança da posição para urinar sendo necessário agachamento com retirada de todas as roupas 
assemelhando-se ao modo como as mulheres urinam e a relutância em urinar próximos de outros homens na posição agachado, parecem caracterizar ainda mais a confusão entre amputação e homossexualidade:

\section{"É de "coca". Eu tenho. De mijar na frente das pessoas eu tenho vergonha. Parecido com mulher." (P7) \\ "Tá saindo um pouco espalhada, me sinto um pouco incomodado." (P6) \\ “Saía um pouco, só que saía um pouquinho, mas só que ela saía fina." (P8)}

É importante ressaltar o sofrimento expresso diante da redução da capacidade de trabalho no campo após a cirurgia. Há preocupação e queixas sobre a limitação do trabalho que era realizado anterior à cirurgia na medida em que a lida na roça exige força física para garantir a subsistência econômica:

“Negócio tá meio difícil pra mim porque eu não sei se vou conseguir mais entrar no mercado de trabalho." (P6)

Alguns não receberam nenhum benefício governamental, e foram ajudados financeiramente por familiares. Na busca por benefício previdenciário houve relato de tentativa de estelionato por pessoas que tentaram lucrar em troca da promessa de um transplante de pênis:

“[...] Ele disse assim. Eu não sei como ele ia fazer. Não era ele, era uma irmã dele que é médica. Não sei se ela mora aqui, não sei. Que diz que ia me ajudar botando um transplante de um pênis ni mim.” (P7)

"[...] Aqui em São Luís me deram 3 mês de encosto (afastamento), aí o rapaz que me falou no assunto, mas o outro disse "não, só quando ele receber a primeira parcela do dinheiro". Aí eu desorientado fiquei assim... eu digo "rapaz, então esse cara tá interessado é no meu dinheiro." (P7)

A incapacidade laborativa é decorrente, principalmente, do linfedema dos membros inferiores após a linfadenectomia inguinal bilateral. Em alguns casos, a linfadenectomia é realizada de forma preventiva pelo risco de perda de seguimento ambulatorial, pois seria necessário consultas trimestrais para vigilância do paciente. Com uma renda familiar de um saláriomínimo é impossível imaginar gastos adicionais a cada 3 meses que incluam as despesas com transporte, alimentação para o paciente e acompanhante, em média duzentos reais para o deslocamento até a capital do estado. Dessa forma, o tratamento fora de domicílio (TFD) conforme a Portaria SAS/MS n 055 de 24/02/1999, assegura acesso ao transporte e a ajuda de custo, quando esgotados todos os meios de tratamento no município onde reside, desde que o local do atendimento esteja, a pelo menos, $50 \mathrm{~km}$ de distância, deve ser implementado para o rigoroso acompanhamento ambulatorial que se faz necessário nos pacientes com câncer de pênis no Maranhão (Portaria nº 55, 1999).

Após a amputação parcial do pênis, os entrevistados relatam mudanças na vida sexual. Mesmo nas cirurgias minimante agressivas quanto ao tamanho do pênis amputado, há uma queixa de perda da sensação de plenitude como homem, de virilidade. Relataram que conseguiam manter a penetração, mas não se sentiam completamente satisfeitos, em termos de orgasmo. Há algo que falta, que não se completa como antes:

“Me sinto, me sinto MENOS HOMEM. A sensação não é como ter normal. Porque eu acho que a alegria do 'homi' ... acho que é o pênis da pessoa." (P4) 
Para os homens que se submeteram à amputação total houve reações contraditórias. Para uns, o objetivo passou a ser manter-se vivo e a vida sexual e o orgasmo perderam alguma importância:

"Agora é só viver. Pro 'pobrema' que tava vindo. O que eu quero é viver." (P1)

No outro extremo, um entrevistado inconformado deseja restaurar o pênis após a amputação total através de um transplante, buscando segundo suas palavras, algo mais que uma figura de homem:

"Que eu só tô na figura de um homem. É 'pruquề' eu não tenho pênis. Se tivesse ficado um pedaço e tivesse jeito de botar um transplante ia ser bom." (P7)

A cirurgia de amputação alcança e repercute em toda a comunidade masculina ao redor, na vizinhança, no círculo de amizades com falas homofóbicas e preconceituosas, trazendo novamente mistura da ideia de amputação e homossexualidade, como se o tamanho do pênis garantisse também a opção sexual:

"Eu recebi na boa. Ele era meu amigo demais. Ele falou: 'Rapaz, ouvi dizer que agora tu nem é mais homem, tu é viado e tal." (P5)

Diante da diminuição ou ausência do pênis, transfere-se para a mulher a importância imputada ao órgão, afirmando que nenhuma mulher aceitaria um homem amputado:

"A mulher casa com o homi por causa daquele pêni." (P7)

Alguns argumentos são usados para justificar para as mulheres o porquê do pênis diminuído, como na fala de um paciente que explicou que um segmento do pênis foi retirado para realizar um enxerto na coxa. Diante da deficiência destas justificativas as relações sexuais aconteciam no escuro:

“Olha, eu fui operado aqui na lateral...", isso foi até um negócio errado que eu acho que eu fiz e não foi só pra uma mulher, eu acho que eu falei pra 2 mulher ou 3: "O médico... como eu fui operado e ia ficar um lado fundo aqui na minha coxa, o médico achou que a carne melhor que tinha pra fazer esse procedimento pra não ficar fundo, era só a do pênis." (P8)

A redução do tamanho do pênis é o que produz mais sofrimento e impacto no retorno a vida sexual independente do segmento amputado, mesmo mínimo que seja. Veale et al. (2015), encontraram somente 2,8 \% de 15.521 mil homens com pênis pequeno ao aplicar escala que avalia a dimensão peniana, e encontraram que é uma minoria de homens que possuem pênis fora de um padrão métrico. Smith et al. (2017), informa que há insatisfação em relação ao tamanho do pênis e um desejo de realizar procedimentos para aumentar o comprimento, a circunferência e deixá-lo mais retilíneo somente por descontentamento com a imagem da região genital. Avaliamos que representação social da masculinidade se ancora na idealização de um pênis sem alterações anatômicas, que seja grande, retilíneo. Esta imagem (Nogueira \& Grillo, 2020) compõe a representação social alimentada por símbolos e conceitos que são gerados por crenças e ideais e que se combinam com as falas dos entrevistados dessa pesquisa. 


\section{Conclusão}

Esta pesquisa atingiu os objetivos propostos de discutir a demora dos homens em procurar assistência médica no SUS a partir das primeiras lesões visíveis de câncer no pênis. Esta doença parece possuir e seguir um perfil de baixa escolaridade, baixos recursos econômicos e forte ruralidade.

A representação social que ancora a discussão na ameaça pela doença é a diminuição no tamanho do pênis, mais que o medo da morte, conforme pode-se observar na música de João do Vale e na obra de Leonardo da Vinci. Nestas duas expressões artísticas, tão distantes no tempo (500 anos) e tão próximas na representação social coletiva atual sobre o pênis, ele é cilíndrico (pica), muito duro (pau e a obra de da Vinci), e sempre pronto para muitas repetições (a pipira).

Os moradores do interior do estado do Maranhão levam em torno de 6 meses para procurar atendimento de saúde a partir da visualização da primeira lesão, a qual denominam de "borbulha", e levam mais de 1 ano para obter atendimento médico especializado. Este percurso dentro do SUS é marcado por não observância da propedêutica médica, onde muitos são considerados examinados sem tirar a roupa, portanto sem exame físico, pois em alguns pacientes, mesmo tendo sido visualizada o tumor não houve a suspeita diagnóstica de lesão cancerosa. Há a figura do "atravessador do SUS", onde alguns funcionários cobram taxas para facilitar o acesso ao hospital especializado em câncer na capital do estado.

A figura do balconista da farmácia, farmacêutico ou não, cujo estabelecimento é presente em quase todos os municípios e com atendimento 24 horas e até em finais de semana, revelou-se a figura mais importante para o primeiro contato de ajuda, embora com prescrição de uso tópico e equivocado, adequado para alergias ou micoses e não para lesão tumoral. O balconista da farmácia frequentemente funciona como confidente da dificuldade vivenciada, a qual não é comentada com a parceira por medo da acusação de doença sexualmente transmissíveis e as explicações sobre a contaminação que poderiam abalar o casamento. Verificamos também que há uma explicação confusa para a cirurgia de amputação que desloca o homem para a dúvida de homossexualidade, onde o tamanho do pênis e sua integridade é que serão os marcadores da virilidade, perdida na amputação total. Vale ressaltar que a ocorrência frequente de esvaziamento ganglionar pode ocorrer por dificuldade de acesso deste paciente ao SUS do que por indicação cirúrgica imediata. Este esvaziamento produz intenso sofrimento na medida em que causa edema de membros inferiores e pode inabilitar, total ou parcialmente, para o trabalho físico pesado na roça, que costuma ser a forma de sobrevivência econômica destes homens.

Sugere-se o desenvolvimento de estudos que visem auxiliar no reconhecimento de lesão tumoral no pênis por parte dos profissionais de farmácia, considerando sua capilaridade no interior do estado e grande facilidade de acesso, capacitação da equipe de saúde da Atenção Primária, aprimoramento do agendamento de consultas no SUS, além do acompanhamento multidisciplinar dos indivíduos que se submeteram a amputação do pênis.

\section{Referências}

Audenet, F., \& Sfakianos, J. (2017). Psychosocial impacto of penile carcinoma. Transl. Androl. Urol., 6(5), 874-878.

Alves, R. S. S., Silva, L. C., Leite, A. C., Silva, E. R., Pereira, B. L., Barbosa, T. C., Santos, R. C. A., Santos, S. F., Cunha, J. A., Sales, D. F. S., Silva, J. K. A., \& Almeida, L. F. (2021). A inclusão do homem nas consultas de pré-natal de suas parceiras em serviços de Atenção Primária à Saúde. Research, Society and Development, 10(6), Artigo e55810615768. https://doi.org/10.33448/rsd-v10i6.15768

Carneiro, V. S. M., Adjuto, R. N. P., \& Alves, K. A, P. (2009). Saúde do homem: identificação e análise dos fatores relacionados à procura, ou não, dos serviços de atenção primária. Arq. Cienc. Saúde UNIPAR, 23(1), 207-217. https://doi.org/10.25110/arqsaude.v23i1.2019.6521

Carrara, S. (1996). Tributo a vênus: a luta contra a sífilis no Brasil, da passagem do século aos anos 40. FIOCRUZ. http://books.scielo.org/id/q6qbq

Coelho, R. W. P., Pinho, J. D., Moreno, J. S., Garbis, D. V. O, Nascimento, A. M. T., Larges, J. S., Calixto, J. R. R., Ramalho, L. N. Z, Silva, A. A. M., Nogueira, L. R., Feitoza, L. M., \& Silva, G. E. B. (2018). Penile cancer in Maranhão, Northeast Brazil: the highest incidence globally? BMC Urology, 18(50). https://doi.org/10.1186/s12894-018-0365-0

Coition of a Hemisected Man and Woman (2021).In Wikipedia.https://pt.wikipedia.org/wiki/Ficheiro:Coition_of_a_Hem isected_Man_and_Woman.jpg 
Dib, R. V., Gomes, A. M. T., Ramos, R. S., França, L. C. M., \& Marques, S. C. (2020). O câncer e suas representações sociais para pacientes oncológicos. Research, Society and Development, 9(9), Artigo e187997134. http://doi.org/10.33448/rsd-v9i9.7134

Globocan. (2021, 28 de julho). Cancer today. World Health Organization. https://gco.iarc.fr/today/online-analysis-map?v=2020

Hurston, Z. N. (2021). Prescrição de Doutores Raiz. Ayé: Revista de Antropologia, 79-86. https://revistas.unilab.edu.br/index.php/Antropologia/article/view/650

Jodelet, D. (2003). 1. Représentations sociales: un domaine en expansion. In Jodelet, D. (Eds.), Les représentations sociales (pp. 45-78). Presses Universitaires de France. https://doi.org/10.3917/puf.jodel.2003.01.0045

Lei $n^{\circ}$ 8362, de 09 de dezembro de 2016. (2016). Dispõe sobre o calendário oficial de eventos do município de Blumenau e consolida a legislação municipal referente a eventos, datas comemorativas e feriados do município. https://tinyurl.com/3js $4 \mathrm{cvfn}$

Lindoso, G. S., Barros, E. G, D., Miranda, L. F. N., Campelo, B. C., Moura, K. C. F., Freitas, L. A., \& Cordeiro, G. V. B. (2018). Epidemiologia e estratégias de prevenção do câncer de pênis no estado do Maranhão. Rev. Investig, Bioméd. São Luís, 10(3), 237-242. https://doi.org/10.24863/rib.v10i3.331

Lopes, R. S. S. P., Sardagna, M. C., \& Iervolino, S. A. (2017). Motivos que levam os homens a procurar um serviço de pronto atendimento. Enfermagem Revista, 20(2), 151-165. http://periodicos.pucminas.br/index.php/enfermagemrevista/article/view/16331

Marková, I. (2017). A fabricação da teoria de representações sociais. Cadernos de Pesquisa, 47(163), 358-375. http://doi.org/10.1590/198053143760

Medeiros, L. F., \& Cabral, A. L. A. (2019). Ser homem: um estudo sobre as masculinidades no interior do Nordeste brasileiro. Investigação Qualitativa em Saúde, 2, 559-568. https://proceedings.ciaiq.org/index.php/CIAIQ2019/article/view/2126

Minayo, M. C. S. (2014). O desafio do conhecimento: pesquisa qualitativa em saúde. (14a ed.). Hucitec.

Ministério da Saúde. (2008). Política nacional de atenção integral à saúde do homem. https://bvsms.saude.gov.br/bvs/pub licacoes/politica_nacional_atencao_homem.pdf

Moreira, K. S., Lima, C. A., Vieira, M. A., \& Costa, S. M. (2017). Educação permanente e qualificação profissional para atenção básica. Revista Saúde e Pesquisa, 10(1), 101-109. https://doi.org/10.17765/2176-9206.2017v10n1p101-109

Moscovici, S. (2009). Representações sociais: investigações em psicologia social. (6a ed.). Vozes.

Nogueira, K., \& Grillo, M. D. (2020). Teoria das Representações Sociais: história, processos e abordagens. Research, Society and Development, 9(9), Artigo e146996756. http://doi.org/10.33448/rsd-v9i9.6756

Oliveira, D. C., Cecilio, H. P. M., Gomes, A. M. T., Marques, S. C., Spindola, T., \& Pontes, A. P. M. (2017). A universalização e o acesso à saúde: consensos e dissensos entre profissionais e usuários. Cad. Saúde Colet., 25(4), 483-490. https://doi.org/10.1590/1414-462X201700040078

Pereira, N. M. (2000). Focalização peniana da perturbação corporal dismórfica correlatos físicos e psicológicos. [Dissertação de mestrado, Universidade Lusófona de Humanidades e Tecnologias]. https://tinyurl.com/2fkc2a2m

Pinto, G. R. S., Melo, M. M. C., Leal, V. G., Costa, J. S., Dias, L. S., \& Teixeira, C. V. P. (2021). Contribuição farmacêutica na promoção da saúde em farmácias e drogarias. Research, Society and Development, 10(3), Artigo e41910313614. http://doi.org/10.33448/rsd-v10i3.13614

Portaria ${ }^{\circ}$ 55, de 24 de fevereiro de 1999. (1999). Dispõe sobre a rotina do Tratamento Fora de Domicilio no Sistema Único de Saúde - SUS, com inclusão dos procedimentos específicos na tabela de procedimentos do Sistema de Informações Ambulatoriais do SIA/SUS e dá outras providências. https://bvsms.saude.gov.br/bvs/saudelegis/sas/1999/prt0055_24_02_1999.html

Santos, E. A. (2020). Sexualidade: seu status filosófico e psicológico. Scala.

Schraiber, L. B., Figueiredo, W. S., Gomes, R., Couto, M. T., Pinheiro, T. F., Machin, R., Silva, G. S. N., \& Valença, O. (2010). Necessidades de saúde e masculinidades: atenção primária no cuidado aos homens. Cad. Saúde Pública, 26(5), 961-970. https://doi.org/10.1590/S0102-311X2010000500018

Separavich, A. M., \& Canesqui, A. M. (2013). Saúde do homem e masculinidades na Política Nacional de Atenção Integral à Saúde do Homem: uma revisão bibliográfica. Saúde Soc. São Paulo, 22(2), 415-428. https://doi.org/10.1590/S0104-12902013000200013

Silva, E. P., \& Correia, I. M. (2021, 28 de julho). Sexualidade nordestina: raízes e expressões. APAC. https://www.apacp.org.br/diversos/artigos/sexualidadenordestina-raizes-e-expressoes/

Silva, J. A. T., Lima, M. J., Elias, B. K., \& Silva, N. M. M. G. (2021). Percepções sobre o autocuidado masculino: uma revisão de literatura. Brazilian Journal of Development, 7(2), 20766-20777. https://doi.org/10.34117/bjdv7n2-631

Silva, S. E. D., Almeida, M. R., Corrêa, A. C. A., Monteiro, J. M. N., Gonçalves, P. J. C., Carneiro, R. B., Gomes, S. A. C., Bravo, T. B., Amaral, T. L., Alves, P. S., Santos, J. A., Cunha, N. M. F., \& Vasconcelos, E. V. (2015). Câncer - uma doença psicossocial: câncer no homem e a herança da cultura machista. Revista Eletrônica Gestão \& Saúde, 6(1), 606-616. https://periodicos.unb.br/index.php/rgs/article/view/2584

Smith, N. K., Butler, S., Wagner, B., Collazo, E., Caltabiano, L., \& Herbenick, D. (2017). Genital Self-Image and Considerations of Elective Genital Surgery. Journal of Sex \& Marital Therapy, 43(2), 169-184. https://doi.org/10.1080/0092623X.2016.1141820

Soares, A., Carvalho, I. T., Fonseca, A. G., Junior, A. M. A., Leite, C. H. B., Bastos, D. A., Soares, J. P., Leite, K. R. M., Filho, M. R. B., Coelho, R. W. P., Cavallero, S. R., Zequi, S. C., \& Calixto, J. R. R. (2020). Penile cancer: a Brazilian consensus statement for low- and middle-income countries. J Cancer Res Clin Oncol., 146, 3281-3296. https://doi.org/10.1007/s00432-020-03417-1

Sousa, K. N., \& Souza, P. C. (2021). Representação social: Uma revisão teórica da abordagem. Research, Society and Development, 10(6), Artigo e38610615881. http://doi.org/10.33448/rsd-v10i6.15881 
Research, Society and Development, v. 10, n. 13, e398101321454, 2021

(CC BY 4.0) | ISSN 2525-3409 | DOI: http://dx.doi.org/10.33448/rsd-v10i13.21454

Souza, I. B., Tenório, H. A. A., Junior, E. L. G., Lima, I. C. M., Santos, R. F. E. P., \& Viana, L. S. (2019). Sexualidade para o homem em tratamento oncológico. Revista Eletrônica Acervo Saúde, 11(4), Artigo e275. https://doi.org/10.25248/reas.e275.2019

Vale, J., \& Batista, J. (1962). Xote da pipira [Partitura vocal]. RCA Victor.

Veale, D., Miles, S., Bramley, S., Muir, G., \& Hodsoll, J. (2015). Am I normal? A systematic review and construction of nomograms for flaccid and erect penis length and circumference in up to 15,521 men. BJU Int., 115, 978-986. https://doi.org/10.1111/bju.13010

Vieira, C. B., Feitoza, L., Pinho, J., Teixeira-Júnior, A., Lages, J., Calixto, J., Coelho, R., Nogueira, L., Cunham I., Soares, F., \& Silva, G. E. B. (2020). Profile of patients with penile cancer in the region with the highest worldwide incidence. Sci Rep., 10, Artigo 2965. https://doi.org/10.1038/s41598-020-59831-5

Wakiuchi, J., Oliveira, D. C., Marcon, S. S., Oliveira, M. L. F., \& Sales, C. A. (2020). Meanings and dimensions of cancer by sick people - a structural analysis of social representations. Rev Esc Enferm., 54, Artigo e03504. https://doi.org/10.1590/S1980-220X2018023203504 